\title{
CASO SAN PABLO
}

\section{Luís Aníbal Maggio}

Professor titular de Direito Romano na Faculdade de Direito, Ciências Políticas e Sociais da Universidade de Morón (Argentina)

anibalmaggio@yahoo.com.ar

1:El proceso seguido al Apóstol Pablo se inscribe en el período histórico (siglo I a III p.C) caracterizado como de "las persecuciones" a los profesantes de la nueva religión, los cristianos, pero ofrece al menos dos particularidades:

1: Se trata de un proceso penal contra un "ciudadano romano". En los casos de los demás perseguidos, se los mencionan como "judíos", "cristianos", "nazarenos" sin aparecer el tema de la ciudadanía. 2: Hay discrepancia entre los autores sobre los fundamentos jurídicos de las persecuciones. Para algunos (Mommsen, de Francisci, etc) estuvieron apoyadas en las leyes penales generales del sistema romano desde los delitos como "perduellio" y/o "crimen maiestatis", especialmente la negativa de rendir culto al emperador, hasta leyes contra la magia y los sacrilegios. Para otros, se habría tratado de "leyes especiales" comenzando por un eventual "Institutum neronianum", mencionado por Tertuliano, que habría dictado Nerón luego del incendio de Roma y habría oficiado como paradigma persecutorio en adelante $\left({ }^{1}\right)$. Sin embargo, por más que se lea y relea el único documento histórico estimado confiable $\left({ }^{2}\right)$ sobre este proceso (Los Hechos de los Apóstoles), no se hallará mención a ningún delito penal romano ni a alguna ley especial. Para los romanos era un asunto puramente religioso entre judíos. "Este hombre es una verdadera peste; él suscita disturbios entre todos los judíos y es uno de los dirigentes de la secta de las nazarenos", alega Tértulo en contra de Pablo. "Lo que había entre ellos eran no sé qué discusiones sobre su religión y sobre un tal Jesús que murió y que Pablo dice que vive", informa Festo al rey Agripa. "Pero ahora quisiéramos oírte exponer lo que piensas porque sabemos que esta secta encuentra oposición en todas partes", los judíos piden a Pablo $\left({ }^{3}\right)$.

El famoso "institutum neronianum", de haber existido, fue obviamente posterior al caso de Pablo, que transcurre entre los años 58 al 60. La única norma anterior que es posible colectar a través de "Los Hechos" y de Suetonio $\left({ }^{4}\right)$, es un edicto del Emperador Claudio (41-54) que data entre los años 50/52, expulsando

\footnotetext{
Ruiz Bueno: Actas de los mártires. BAC: 82 y 216; BAC: Historia de la Iglesia: IX,II,4; Cllevaert, Ehrhard, Kirsch. Contra. Hughes P: Historia de la Iglesia. Ed.Herder,33.

E. Renán. San Pablo. Ed. Nova, cap.1.

3 Los Hechos de los Apótoles (HE): 24.5;25.19; 28.22.

${ }^{4}$ HE: 18,1. Suetonio: Vita Caesarum, Claudius, 26, Tiberius Nero 36. Tácito: Anales XV,44.
} 
a los judíos de Roma: "Iudeos, impulsore Chresto, assidue tumultuantes, Roma expulit" ("Claudio expulsó de Roma a varios judíos que promovían turbulencias por instigación de un cierto Cristo"). Mal podría ser de aplicación en este caso el edicto claudiano cuyo objeto era expulsar a judíos de Roma no traerlos, como reclamara Pablo. Los Hechos refieren que Pablo se encontró en Corinto con Aquila y su mujer Priscila, que precisamente habían sido obligados a salir de la ciudad capital a raíz de este edicto.

2: Veamos el relato de Lucas $\left(^{5}\right)$ :

Pablo regresa a Jerusalén y tiene disputas con judíos y judíos-cristianos que lo acusan de no cumplir con la ley mosaica e introducir además paganos en el tempo. Se produce una batahola y se apoderan de Pablo con intenciones de matarlo cuando aparece el tribuno Claudio Lisias que se lo saca de las manos y ordena lo aten con cadenas y lo lleven a la fortaleza (torre Antonia, noroeste del templo). Pablo pide y se le permite hablar, cuenta su historia confesándose judío, pero los acusadores insisten en que lo eliminen. El tribuno lo lleva a la fortaleza y ordena que lo azoten. Pablo como defensa pregunta "si les está permitido azotar a un ciudadano romano sin haberlo juzgado". Al enterarse, Lisias se alarma por haber encadenado a un ciudadano romano, ordena que le saquen las cadenas y convoca para el día siguiente a los sacerdotes y al Sanedrín. En la reunión se produce un altercado entre Pablo y el Sumo Sacerdote Ananías; al declararse Pablo fariseo, discuten fariseos y saduceos y como la disputa se hacía cada vez más violenta, Licias, temiendo por la seguridad de Pablo lo manda de nuevo a la fortaleza. Los judíos traman asesinarlo, se entera un sobrino del apóstol que por medio de un centurión informa al tribuno. El tribuno le pide guarde absoluto secreto, llama a dos centuriones, les ordena preparen soldados y caballos (incluso para Pablo) y dispone enviarlo de noche con custodia militar y una carta explicativa al gobernador Félix.

3: Los hechos transcurren en la lejana "provincia" de Judea e intervienen un "tribuno", un "gobernador" y el Consejo Supremo de los judíos o "Sanedrín".

En el año 6 d.C, a consecuencia de las disputas entre los herederos de Herodes y el destierro de Aquelao, Augusto convierte a Judea en una provincia romana "de segundo orden" $\left.{ }^{6}\right)$ con un número ínfimo de tropas de a pie y a caballo.

En su origen se denominó "provincia" a la competencia o división del "Imperium" entre los magistrados colegas $\left({ }^{7}\right)$. Posteriormente se designaron como "provincias" las regiones conquistadas por los romanos fuera de Roma. Augusto las dividió en "imperiales" (del Emperador) y "senatoriales" (del Senado). Las

HE: $21 / 28$

6 T. Mommsen: El Mundo de los Césares. FCE, México,,335.

7 T. Mommsen. Historia de Roma. Joaquin Gil Editor. Apéndice V. 
primeras, generalmente más apartadas y expuestas a los ataques de los bárbaros, eran gobernadas por el Emperador por intermedio de sus legados (legati Caesaris); los súbditos pagaban un "tributum" (impuesto) al fisco (tesoro del Emperador). Las segundas eran gobernadas por el Senado de Roma; los súbditos pagaban un "stipendium" (impuesto) al "aerarium" (tesoro del Senado). La división diárquica subsiste hasta la época de Diocleciano (284-305) que con la "tetrarquía" (gobierno de cuatro) reorganiza el imperio en cuatro prefecturas. La nueva provincia donde transcurren los hechos narrados dependía del Emperador.

Al designarse con el vocablo "provincia" la porción de territorio ocupado en que ejerce la jurisdicción el magistrado romano, se le asigna la significación de "campo vencido" $\left({ }^{8}\right)$ Esta etimología reconocería su origen en el verbo "vinco" (is,vici,victum,cere) que Julio César hiciera famoso (veni,vidi,vinci). Sin embargo, podría reconocer otra significación. Las "provincias" eran gobernadas por magistrados romanos que habían concluido el período de su magistratura y eran enviados como "presidentes" o "gobernadores" y, en las imperiales, como "legados" (legati Caesaris) por lo general con la jerarquía del cargo desempeñado en Roma anteponiendo al título el prefijo "pro" $\left({ }^{9}\right)$ : delante de, frente de, en lugar de, como si ("pro-consule", "pro-praetore", etc) Los cargos desempeñados en las provincias, a más del honor, para muchos, como para Verres, significó una posibilidad de resarcirse de los cuantiosos gastos de sus campañas electorales, no precisamente por medios honorables. El verbo latino "vincio-is-xi-ctum-ere" significa unir,atar,ligar. "Vinceus-a-um": lo propio para atar (Plauto). De modo que, desde este punto de vista, "pro-vincia" también tendría la significación de lo (territorio) unido, atado, ligado (gobernado) fuera de los límites de la Urbe.

A hora bien, en el supuesto del verbo vencer (vinco) habría que preguntar cuál haya sido la significación del "pro" antepuesto. Si tomamos la acepción "a favor de" que también reconoce la preposición "pro", quizá no sería arriesgado entender extensivamente que el hecho de la derrota se consideraba paradójicamente un beneficio para los vencidos, como ha ocurrido tantas veces en la historia cuando un pueblo real o supuestamente más avanzado o civilizado intenta "inculturizar", "mejorar las condiciones", de las poblaciones conquistadas.

El gobernador de la Provincia lo hacía con el título de "prefecto", pero, a partir del año 44, cambia por el de "procurador". Por ello, Pilatos no pudo ser procurador sino prefecto porque el término no existía a la época de Jesús $\left({ }^{10}\right)$. El gobernador, en este caso Felix, residía en Cesarea, en el palacio real de Herodes. Su sede era el "pretorio", pero con frecuencia, especialmente para las festividades

T. Mommsen: Der. Penal Romano, 1, 240. Der. Público Romano, 120.

9 T. Mommsen: Der. Penal Romano, 1,239.

${ }^{10}$ M.Onfray. Tratado de Ateología, 152. 
más importante, como ocurrió en este caso, se trasladaba a Jerusalem $\left({ }^{11}\right)$ donde residía con carácter permanente un jefe militar con título de "tribuno", Claudio Licias en nuestra narración, bajo la dependencia del gobernador. De modo similar a los demás municipios romanos, la nueva provincia se gobernó autónomamente bajo el control de las autoridades romanas. Gran relevancia tuvo el consejo de notables denominado "Sanedrín", al que convocó el tribuno, presidido por el Gran sacerdote al que acompañaban los "Doctores de la Ley". Si bien su competencia era básicamente eclesiástica, el gobierno romano dejó en sus manos prácticamente todas las atribuciones de que gozaban las comunidades helénicas y municipios romanos $\left({ }^{12}\right)$.

Los municipios fueron ciudades-estados conquistadas y anexadas por Roma; generalmente se trataba de comunidades a la que le era concedida la ciudadanía romana con mayores o menores limitaciones (vgr: el derecho a voto - sine suffragio-), pero teniendo una completa organización municipal y una administración autonómica: magistrados, curias y comicios $\left({ }^{13}\right)$.

En Dig. L-XVI,18 podemos leer: "Munus tribus dicitur...Igitur municipes dici, quod munera civilia capiant". "Munus se dice de tres modos.Y así se dice munícipes porque adquieren los cargos civiles.

4: La orden del tribuno de atar a Pablo con dos cadenas y de conducirlo a la fortaleza, nos señalan dos figuras: el arresto y el encadenamiento, a cuyo respecto dice Mommsen: "Entre los romanos, el arresto correspondía a la esfera de coerción del magistrado, absolutamente en este pueblo (romano) no se conoció la cárcel como pena. El arresto, por consiguiente, se hallaba sometido por su propia esencia al arbitrio del magistrado estaba regulado por ley, es decir, podía prescribirse o prohibirse al magistrado, dentro de ciertos límites, hacer uso del arresto; pero por lo general, sólo podía preguntársele por el motivo, no por el fundamento jurídico de tal arresto". El "arresto público" derivaba del encadenamiento (vincire) de los prisioneros de guerra; por lo común se le llamaba también "ligadura". El encadenamiento o ligadura no conllevaba necesariamente el encarcelamiento, pero en la práctica el encadenamiento y el encarcelamiento se confundían ya que, si bien los magistrados podían decretar el arresto sin encarcelamiento, lo regular era que decretasen ambas cosas a la vez, por creer que así lo exigían razones de seguridad" $\left({ }^{14}\right)$.

Las ligaduras no importaban estar físicamente encadenado todo el tiempo ni privaban de modo absoluto de la libertad. El "encadenado" podía ser visitado o ver a sus amigos, realizar sus actividades habituales, disponer de sus bienes,

\footnotetext{
${ }^{11}$ Alvarez Valdez, Ariel: Historia de Israel. UCASgo.del Estero, págs. 299/300.

12 T. Mommsen. El mundo.op.cit.336.

${ }^{13}$ E. Petit. Trat.Elem.Derecho Rom. Albatros, 117; Mommsen, T: Der. Púb.Romano.

${ }^{14}$ T. Mommsen. Op. cit.
} 
etc. Las ligaduras regularmente se desataban durante el proceso, como dispuso el tribuno Licias al hacerlo comparecer ante él y los sumos sacerdotes y el Sanedrín; tampoco se permitían en la "custodia libera", estado en que Pablo estuvo luego bajo Félix como veremos infra $\left({ }^{15}\right)$.

La "custodia militar" era la encargada de velar por la seguridad de los prisioneros en tránsito, que marchaban ligados por una cadena en la mano derecha atada a la mano izquierda del custodio. Fuera de Roma todo comando militar tenía atribuciones para arrestar no solamente por delitos militares sino también civiles. La "custodia militaris" que en principio correspondía a la milicia, se fue aplicando progresivamente al arresto de civiles, especialmente en caso de ciudadanos importante (VIP diríamos hoy). Pablo es enviado pues bajo "custodia militaris" con una comitiva de 470 soldados. ¡ Nunca tuvo un apóstol más asistencia militar! exclamaba monseñor Straubinger $\left({ }^{16}\right)$.

El Digesto (L, XVII,224) aclara: "Vinculorum appelatione vel privata vel publica vincula significant, "custiodiae" verum tantum publicam custodiam": "Con la palabra "ataduras" significan ataduras privadas, pero con la de "custodia" solamente la "custodia pública".

Lo custodian dos centuriones. El de centurión era un cargo militar con mando sobre cien personas por lo que en este caso se requerían dos. Era el más alto al que podían llegar los soldados y generalmente la puerta de entrada al orden ecuestre $\left({ }^{17}\right)$. "Centurión o soldado distinguido", dice Suetonio.

Modestino $\left({ }^{18}\right)$ recomienda no confiar la custodia a soldados jóvenes, proponiendo que sean dos, no uno. Y si se les escapan los reos, castigarlos o cambiarlos de milicia. "Non est facile tironi custodia credenda, nam ea prodita is culpa reus est, qui eam ei comitidit. 1: Nec uni, sed duobus custodia comittenda est. 2: Qui si negligencia amiserint. Pro culpae vel castigantur, vel militiam mutant". "(No se ha de confiar fácilmente la custodia al soldado bisoño porque, desatendida aquella, es reo de culpa el que se la encomendó. 1: Y no ha de ser encomendada a uno solo sino a dos. 2: Y si por negligencia hubiere perdido a los presos, o son castigados según su culpa o cambian de milicia”).

La carta de Lisias al gobernador Félix rezaba: "Aqui te mando un hombre que fue detenido por los judios y cuando ya lo iban a matar, enterándome que era ciudadano romano, intervine con mis soldados y pude rescatarlo. Queriendo saber exactamente de qué lo acusaban, lo hice comparecer delante del tribunal judio, pero comprobé que se lo acusaba por cuestiones relativas a la religión

\footnotetext{
15 Josefo: Antiq-VI,7; Renan: op.cit,358; HE 22.30-31. Mommsen, op.cit. II,311.

16 Mommsen, op.cit.1,318; Renan: op.cit.354; RB, 212; Straubinger: Sagr.Biblia. Ed.Guadalupe.HE: 23.23, nota.

${ }^{17}$ Fiedlaender, Ludwig. La Sociedad Romana. FCE,155. Suetonio: Vital Caesarum. Vesp. I.

${ }^{18}$ Dig. XLVIII,III, 14.
} 
de los judios y que no había contra él ningún cargo que mereciera la muerte o la prisión. Informado que se tramaba una conspiración contra este hombre, he querido enviarlo alli enseguida, ordenando también a sus acusadores que te expongan los cargos que tengan contra él. Adios"

La carta de Lisias era un "elogium" es decir, un informe sobre los hechos que motivaban el envío del reo al Superior. "Illud a quisbusdam observari solet, tu, cum cognovit et constituit, remittat illum cun elogio ad eum, qui provinciae preest, unde is homo est; quod ex causa faciendum est" (Se suele practicar por algunos que, cuando conoció el caso y resolvió, lo remite con una relación al que es Presidente de la provincia de donde es aquel hombre; lo que se ha de hacer en virtud de la causa"). Estas relaciones no gozaban de mucho crédito por lo que en cierta forma su escasa confiabilidad podría hasta mejorar la situación del reo. El Digesto las descalifica: Divus Hadrianus Iulio Secundo ita rescripsit: et alias rescriptum est, non esse utique epistolis eorum credendum, qui quasi damnatos ad Praesidem remiserint. Idem de irenarchis praeceptum est, quia omnes ex fide bona elogia scribere compertum est". ( El Divino Adriano respondió así por escrito a Julio Segundo: También otras veces se respondió por rescripto que no se ha de dar ciertamente crédito a las cartas de los que hubieren remitido como condenados. Lo mismo se preceptuó respecto de los irenarcas, porque se ha visto que no todos escriben de buena fe su relaciones). El rescripto de Adriano, de fecha obviamente posterior, recuerda rescriptos anteriores lo que permiten columbrar que una larga tradición de sospechas recaía sobre estos partes $\left({ }^{19}\right)$.

Los "irenarcas" eran funcionarios militares-municipales encargados de perseguir a los ladrones de caminos $\left({ }^{20}\right)$.

Según el relato de los Hechos, Lisias en cierta forma revela alguna envidia al manifestar que le había costado mucho dinero conseguir la ciudadanía romana, mientras Pablo le enrostra que él la tiene de nacimiento. Con respecto a la posibilidad de una doble ciudadanía (hemos visto que Pablo también se confiesa también judío fariseo), el prof. Tabosa Pinto menciona una tesis de Mommsen, con base en Cicerón, negando la posibilidad de la doble ciudadanía y la contraria de Franceso de Martino apoyado precisamente en la situación del apóstol Pablo $\left({ }^{21}\right)$

El tribuno se entera de que Pablo era ciudadano romano después de haberlo salvado de la turba y arrestado, pero en la carta informa que lo hizo porque se había enterado que era ciudadano romano. Al parecer, la táctica política de autoelogiarse para mejorar posiciones viene de lejos, pero si, como manifiesta posteriormente,

\footnotetext{
${ }^{19}$ HE: 23,23-31; Celso. Dig. XLVIII.III,11,1, 6.Renan, op.cit.354.

${ }^{20}$ Mommsen, op.cit. 1,313.

${ }^{21}$ HE: 23,28. Agerson Tabosa Pinto. XV Congreso Latinoamericano de Derecho Romano. Morelia,Michoacán, México, 2006
} 
lo sacó de las manos de los tumultuantes enterado que era ciudadano romano, peor para Lisias por el trato poco cortés que luego le dispensó $\left.{ }^{(22}\right)$.

Sin perjuicio de ello, se deduce de este pasaje que las cuestiones religiosas no conformaban ningún cargo para el derecho penal romano, mucho menos susceptibles de pena de muerte o prisión, lo que deviene interesante con relación al tema de la base jurídica de las persecuciones. Es un argumento en que debilita la tesis que las atribuye a la violación de leyes penales vigentes.

5: Vemos en este pasaje al tribuno Lisias haciendo uso de la "coercitio".

La "coercitio", coerción administrativa, deriva de la idea plenitud del poder ("imperium") de los magistrados que en un principio y en cabeza del "rex", era absoluto. Medidas punitivas de orden administrativo y penal fueron acotando sus alcances con ciertas restricciones que, de todas maneras, dejaron subsistente un amplísimo margen de poder en manos de los magistrados.

La "coercitio" estaba conformada por el del poder de los magistrados para imponer penas válidamente dentro de la ciudad sin necesidad de que las mismas fueron confirmadas por los comicios y sin necesidad de que interviniera el jurado. $\mathrm{Si}$ al magistrado corresponde el derecho de dar órdenes, no era concebible darlas sin medios para hacerlas cumplir coactivamente. No obstante, al estar regulado el poder de los magistrados respecto de los ciudadanos, todo acto que excediere los límites de las regulaciones se consideraba un acto privado sometido a la esfera de las acciones penales. El poder del magistrado podía manifestarse con respecto a personas no sometidas a la represión ordinaria, a regímenes de especial rigurosidad como los militares o simplemente por tratarse de hechos considerados nocivos para la comunidad sin estar legalmente previstos como punibles. En suma, el magistrado disponía de un poder suficiente para hacer cumplir eficazmente los deberes propios de su cargo.

Este tipo de coerción se manifestó, por ejemplo, en los casos de "superstitio externa". Si bien el culto a los dioses extranjeros no era considerado un delito, en muchos casos las ceremonias u otras prácticas religiosas no fueron recibidas con beneplácito y suscitaban reprobación social y política, especialmente cuando, como ocurría con cultos egipcios, eran extraños a las modalidades romanas. Desde la prohibición de ceremonias públicas, la clausura de locales, la destrucción de altares o secuestros de objetos litúrgicos hasta el destierro de adeptos fueron formas de ejercicio de la "coercitio". Las reuniones y celebraciones, el ósculo de la paz, la eucarestía y otras particulares exteriorizaciones de los cristianos sin duda hubieron de suscitar intrigas y desconfianzas en la mentalidad romana acarreando en consecuencia medidas de coerción administrativa. Como en la famosa carta

${ }^{22}$ HE: 21,33; 23,23-31 
de Plinio a Trajano, en muchos otros documentos el cristianismo era tildado de "superstición absurda".

Una primera y marcada limitación está señalada por la distinción entre un derecho de punición militar, derecho de guerra ("imperium militiae"), que era ilimitado y un derecho punitivo doméstico ("imperium domi") reducido a los ciudadanos romanos, no así a los no ciudadanos, no libres y mujeres a quienes no beneficiaba.

Otro punto lo marca la distinción entre infracciones religiosas e infracciones o delitos civiles. El rey tuvo atribuciones para imponer la pena de muerte a todo ciudadano calificado de "ateo" por el pontífice máximo, pero al irse separando las esferas de lo religioso y civil, no se le transfirió a las autoridades religiosas ese poder y no hubo ningún delito ni procedimiento sacral o religioso en adelante. Dentro del ámbito religioso el Pontífice Máximo gozaba de cierta posibilidad de coerción sobre los sacerdotes y los sacerdotes sobre los particulares, pero sin facultades de imponer penas o solicitar el auxilio de los magistradotes.

El derecho de coerción correspondía a los magistrados "cum imperio", a los tribunos y a los magistrados fuera de los límites de la ciudad. La "coerción inferior", generalmente imposición de multas, correspondía a los magistrados menores, censores, autoridades municipales, etc.

La base de la coerción del magistrado era, dentro de los límites de Roma, el "imperium" regulado; fuera de sus límites, el "imperium" libre y discrecional. Los condicionamientos o regulaciones fueron obra de las costumbres, vgr. la exigencia de publicidad, la obligación de conceder audiencia y oír al inculpado, el señalamiento de plazos dados a conocer al mismo, la posibilidad de suspender de la resolución por el juez hasta estar mejor informado, la autodefensa, sin perjuicio de la eventual asistencia de patrocinadores o defensores, el auxilio de asesores del magistrado. Tales recaudos consuetudinarios en la "civitas" de Roma fueron también generalmente observados a modo de parámetros por los tribunales superiores del Imperio y presidentes de provincias.

La coerción administrativa se ejerce sin que exista tipificación de delito ni procedimiento específico. Se trataba en suma de una respuesta sancionatoria a la insubordinación y la desobediencia al magistrado. Las ofensas a las autoridades, la portación de armas prohibidas, las ventas ilegales, los desórdenes, los actos peligrosos para la seguridad pública, et ita porro entre muchos otros entuertos de la vida urbana, se resolvían mediante coerción. Las penas podían ser de variado tenor: pena capital en caso de "perduellio", faltas militares o de orden internacional, pérdida de la libertad, venta como esclavo, flagelación, arresto, confiscación de bienes, etc.

Lisias se condujo en la emergencia de manera totalmente acorde con sus facultades y normativa usual, pero su situación se resiente y complica por dos razones. La primera por haber hecho encadenar y ordenado azotar a Pablo, aunque hubiere ignorado que era ciudadano romano. Todo ciudadano, y mucho 
más un funcionario, estaba obligado a conocer el derecho vigente sin poder alegar ignorancia, de modo que previamente debió haber tomado la precaución de informarse sobre el "status" de la persona en cuestión; fue pues una actuación negligente. La segunda, porque someter a castigos corporales a un hombre libre era incompatible con una tradición esencial de la cultura jurídica romana. "El sistema penal romano, dice Mommsen, no se desligó completamente de esta concepción originaria, según la cual se hallaban fuera del derecho, fuera de la comunión jurídica, no sólo los no libres, sino también los no ciudadanos y hasta la mujer romana. El derecho penal legislado llegó con el tiempo a ser el mismo para todos, pero la coerción que existía conjuntamente con el derecho penal, es decir, el arbitrio del magistrado, no conoció las limitaciones que hemos estudiado en el cap.IV más que con relación al ciudadano romano". La centralidad del derecho penal romano finca en torno a la figura del ciudadano. El abusar de los medios coercitivos contra ellos no era considerado por el derecho primitivo como un acto en ejercicio del cargo público sino meramente privado cometido por un particular. Si ocasionaba la muerte, se trataba de un homicidio; si causaba alguna otra lesión, injuria. Pero ya Catón (234-149) había celebrado un acuerdo con el pueblo prohibiendo severamente la flagelación cuando la "Lex Porcia" (195 a.C) dispuso castigar con rigor al magistrado que hiciera encadenar, golpear o ejecutar a un ciudadano romano, rigor que fue acentuado por una "lex Sempronia" del tiempo de los Graccos; a su vez las "Leyes Julias" tipificaron como delito de violencia grave la flagelación y tormento contra el ciudadano $\left({ }^{23}\right)$. Esta normativa fue observada en el tiempos de Augusto y Claudio juró respetar al comienzo de su reinado. Sólo a partir de Tiberio y como medida extraordinaria algunos tribunales lo autorizaron y posteriormente es admitida como pena. Obsérvese que Pablo pregunta al tribuno si era lícito castigar a un ciudadano romano "sin haberlo juzgado", es decir, antes de una sentencia que pudiera aplicar la pena de tormento ("supplicia"). El exceso de Lisias lo hizo eventualmente pasable de ser acusado y tener que responder por el delito de injurias como "ofensa intencionada e ilegítima a la personalidad de un tercero".

El título XVIII del libro XLVIII del Digesto está dedica a los tormentos ("de quaestionibus) pero referidos a los esclavos y con muchas precauciones. "In criminibus eruendis quaestio adhibere solet. Sed quando vel auqtenus id faciendum sit, videamus. Et non esse a tormentis incipiendum et divini Agustius constituit, neque adeo fidem quaestioni adhibendum". (Para descubrir el delito se suele aplicar el tormento. Pero veamos cuándo y de qué modo se ha de hacer esto. Y determinó también el Divino Augusto, que no se había de comenzar por el tormento y que por ello no se ha de prestar crédito al tormento).

${ }^{23}$ Op.cit. Penal Romano: 1,331, 87; 2,112 et cap.IX. 
Respecto a personas libres, Mommsen, por un lado, entiende que la ley no extendía la protección a los no ciudadanos, pero, por el otro, expresa que los castigos impuestos por César al magistrado que aplicara tormentos indebidos beneficiaba a los ciudadanos no romanos y que "los castigos corporales y toda otra clase de martirio, a los cuales se acudía en casos semejantes en muchos estados griegos de gran civilización, estuvieron prohibidos en Roma y lo estuvieron, según la tradición que ha llegado a nosotros, desde muy antiguo y no sólo con relación a los ciudadanos romanos, sino con relación a todos los hombres libres en general; cosa no inverosimil si se tiene en cuenta que tanto la libertad como la esclavitud fueron consideradas por el derecho Romano como instituciones internacionales".

En el pasaje citado del Digesto puede también leerse: "Si quis ,ne quaestio de eo agatur, liberum se dicta, divas Hadrianus rescripsit, non esse eum ante torquendum, quam liberal iudicium experiatur" (Si alguno para que no se le sujete a tormento, dijera que él es libre, resolvió por rescripto el divino Adriano, que no ha de ser atormentado antes que se ventile el juicio sobre la libertad)". No ya la ciudadanía sino la libertad (capitis deminutio media) es el límite. Plinio en su carta a Trajano señala que a los hombre libres los ha coaccionado con "amenzas de suplicio", mientras que a las esclavas las ha sometido a tormentos $\left({ }^{24}\right)$.

La carta de Lisias al gobernador Félix rezaba: "Aqui te mando un hombre que fue detenido por los judios y cuando ya lo iban a matar, enterándome que era ciudadano romano, intervine con mis soldados y pude rescatarlo. Queriendo saber exactamente de qué lo acusaban, lo hice comparecer delante del tribunal judio, pero comprobé que se lo acusaba por cuestiones relativas a la religión de los judios y que no había contra él ningún cargo que mereciera la muerte o la prisión. Informado que se tramaba una conspiración contra este hombre, he querido enviarlo alli enseguida, ordenando también a sus acusadores que te expongan los cargos que tengan contra él. Adios"

La carta de Lisias era un "elogium" es decir, un informe sobre los hechos que motivaban el envío del reo al Superior. "Illud a quisbusdam observari solet, tu, cum cognovit et constituit, remittat illum cun elogio ad eum, qui provinciae preest, unde is homo est; quod ex causa faciendum est" (Se suele practicar por algunos que, cuando conoció el caso y resolvió, lo remite con una relación al que es Presidente de la provincia de donde es aquel hombre; lo que se ha de hacer en virtud de la causa"). Estas relaciones no gozaban de mucho crédito por lo que en cierta forma su escasa confiabilidad podría hasta mejorar la situación del reo. El Digesto las descalifica: Divus Hadrianus Iulio Secundo ita rescripsit: et alias

${ }^{24}$ Dig: XLVIII-XVIII,1 y 12; Mommsen, op.cit. I,50 y 396; II,136; Vid.etiam Cod. IX.XLI. Plinio: Epistolarum I,IX,96. 
rescriptum est, non esse utique epistolis eorum credendum, qui quasi damnatos ad Praesidem remiserint. Idem de irenarchis praeceptum est, quia omnes ex fide bona elogia scribere compertum est". (El Divino Adriano respondió así por escrito a Julio Segundo: También otras veces se respondió por rescripto que no se ha de dar ciertamente crédito a las cartas de los que hubieren remitido como condenados. Lo mismo se preceptuó respecto de los irenarcas, porque se ha visto que no todos escriben de buena fe su relaciones). El rescripto de Adriano, de fecha obviamente posterior, recuerda rescriptos anteriores lo que permiten columbrar que una larga tradición de sospechas recaía sobre estos partes $\left({ }^{25}\right)$.

Los "irenarcas" eran funcionarios militares-municipales encargados de perseguir a los ladrones de caminos $\left({ }^{26}\right)$.

La carta (elogium) de Lisias $\left({ }^{27}\right)$ demuestra que las cuestiones religiosas no conformaban ningún cargo para el derecho penal romano, mucho menos susceptibles de pena de muerte o prisión, lo que deviene interesante con relación al tema de la base jurídica de las persecuciones. Es un argumento en que debilita la tesis que las atribuye a la violación de leyes penales vigentes.

6: Pero Lisias además "ordena" a los acusadores que expongan los cargos ante el gobernador. Ello importó dejar de lado la "coercitio" administrativa para impulsar un proceso penal por vía de "accusatio".

Los procesos penales se sustanciaron por dos vías:

a) Cognitio: Lamentablemente la ausencia de formalidades hace prácticamente imposible una exposición detallada y un estudio científico de este instituto procesal $\left({ }^{28}\right)$

El proceso se inicia sin denuncia de parte y es instruido totalmente por el magistrado. Carece de formalidades y el arbitrio del magistrado es amplísimo y determinante. No hay plazos para la iniciación ni para la terminación de la causa; el magistrado puede sobreseerla, abandonarla o retomarla; puede recibir denuncias, citar a testigos, recibir testimonios anticipados, etc. sin condicionamientos, apreciar la prueba y dictar sentencia en función de sus libres convicciones. El interrogatorio al reo debe haber sido el centro de este procedimiento pues el interrogado no podía negarse a contestar. Las únicas limitaciones a la discrecionalidad del magistrado provenían de las costumbres o de la ley (vgr. la prohibición mutilaciones corporales o de tormentos contra ciudadano, la no aceptación de denuncias anónimas (Trajano - Adriano), la inoficiosidad de la declaración del esclavo contra su amo, etc). "Yo les respondi que los romanos no tienen la costumbre de entregar a un hombre

\footnotetext{
${ }^{25}$ HE: 23,23-31; Celso. Dig. XLVIII.III,11,1, 6.Renan, op.cit.354.

${ }^{26}$ Mommsen, op.cit. 1,313.

${ }^{27} \mathrm{HE}: 23,27.21,33 ; 23,23-31$.

${ }^{28}$ Mommsen. Op.cit. I,337.
} 
antes de enfrentarlos con sus acusadores y darle la oportunidad de defenderse", informa "in voce" el gobernador Festo ante Agripa y Berenice $\left({ }^{29}\right)$.

Cuando se introduce la posibilidad de apelación a los comicios y en consecuencia la suspensión del fallo y su eventual anulación, aparece la figura de la "anquisitio", procedimiento preparatorio consistente en una reseña de los fundamentos de la culpabilidad de los condenados y de la sentencia que permitieran sostener la decisión ante el pueblo, frente al cual el juez oficia ahora como Ministerio Público. Tenemos así el procedimiento penal en que intervienen el magistrado y los Comicios que constará de cinco partes: a) la fijación de un término (diei dictio) o emplazamiento; b) la instrucción sumarial (la "anquisitio"); c) la sentencia (iudicatio et multae irrogatio); d) la apelación para ante la comunidad (provocatio) y e) la resolución comicial (iudicium populi).

De todas maneras el "principio de la cognición" en el sentido de que la instrucción de los procesos penales fuera de competencia total y exclusiva del magistrado, se mantuvo en vigor.

El procedimiento inquisitivo o por "cognición" fue de uso corriente en los primeros tiempos bien, que limitado a los ciudadanos y en Roma (de allí su insuficiencia y relativa eficacia), luego de ser sustituido aunque no siempre abolido en la etapa republicana, reaparece al menos en su estructura básica durante el Principado y se acrecienta en la etapa de las persecuciones en masa.

No se tienen noticias de procesos contra cristianos sustanciados ante los Comicios; en general fueron por "cognición" o por el procedimiento "acusatorio" que veremos seguidamente. Cualquiera haya sido la discrecionalidad, arbitrariedad y hasta ferocidad de los magistrados en el uso de su "imperium", las Actas de los mártires testifican que al menos el recaudo esencial mínimo de audiencia y autodefensa del reo no les fue negado a los cristianos sometidos a proceso.

b) Accusatio: Las "Leges Iudiciariae" de Julio César se componía de la "lex iudiciorum publicorum" (de vi publica) y la "lex iudicorum privatorum (de vi privata). El antiguo proceso criminal celebrado con la intervención del magistrado y los comicios, es reformado con la introducción de las "quaestiones" (i.e. determinación de delitos, sus penas y autoridades jurisdiccionales) que importaban la traslación de las formas procesales de los juicios privados al juzgamiento de los delitos públicos como controversia jurídica entre la comunidad y el inculpado.

El sistema de acusación (accusatio) aunque es originario y guarda cierta similitud con los "iudicia privata" $\left.{ }^{30}\right)$ se adscribe a los "iudicia publica" y estaba fundado en la necesidad de reprimir con más energía ciertos delitos ofensivos a los derechos de la comunidad.

${ }^{29}$ Código: . IX,XLIV, 2,3. Vid.etiam Cód. IX IV A,6 1/6. HE: 25.16. Mommsen, op.cit.I,175, 339.

${ }^{30}$ Ulpiano,3, de privatis delict; XLVII, 1; L.92,d. de furt. XLVV,2. Mommsen, I,51,41- II.IX. 
Se inicia por denuncia de un particular que asume el rol de acusador oficiando como representante de la comunidad, instruye la causa y la lleva adelante hasta la sentencia. Una falsa denuncia lo hace pasible de delito de "calumnia". El magistrado se limita a admitir la acción, hacer lugar a las peticiones y controlar la regularidad del proceso.

A partir de la época de los Graccos casi sin excepciones los procesos debieron instruirse en forma acusatoria. En el primer período las persecuciones se desarrollan sin ningún estímulo de autoridad por el proceso ordinario de las leyes y costumbres en vigor. "El antiguo proceso penal no conocía la función del fiscal o ministerio público en la antigüedad, la querella tenía que ser presentada por un particular, a quien incumbía la prueba. Si no había denuncia privada, el juez podía iniciar la causa, pero no tenía obligación de hacerlo, aun cuando se tratara de delitos notorios. Trajano lo habia prohibido expresamente respecto de los cristianos: "conquirendi non sunt; si deferatur et arguantur, puniendo sunt". San Justino esperaba su proceso pero hasta tanto alguien lo denunció, no fue detenido y ejecutado $\left({ }^{31}\right)$.

Sin embargo, durante el Principado readquiere relevancia la figura del magistrado que a su arbitrio puede admitir o no las acusaciones, remitirlas a la vía civil, tomar inquisitivamente decisiones incluso sin que mediara formalmente acusación, etc. De este modo el ámbito de la "cognición" penal se fue ampliando y transformando en una "procedimiento extraordinario" aplicado a numerosos delitos especialmente en procesos ante los delegados del emperador. Ante el tribunal del Emperador actuaba el magistrado que poco a poco va limitando la intervención de las partes hasta abolirla completamente. A partir de Diocleciano los tribunales ordinarios de hecho dejaron de actuar y prácticamente todos los procesos fueron "extra ordinem". En este estado la coerción y el procedimiento penal por cognición llegaron a confundirse $\left({ }^{32}\right)$.

7: El gobernador lee la carta (elogium), pregunta a Pablo de qué provincia era y, al saber que era de Cilicia, dijo "te oiré cuando lleguen los acusadores" y lo hizo poner bajo custodia en el pretorio.

En tan breve despacho se reflejan algunas características interesantes del proceso penal.

El interrogatorio al acusado era un punto central del procedimiento y no sólo el sentimiento del derecho sino también la costumbre se oponían, dice Mommsen a que se dejase de oír al acusado como elemento esencial del derecho a la defensa: "Yo les respondí que los romanos no tienen la costumbre de entregar a un hombre

${ }^{31} \mathrm{RB}, 106 / 7$.

${ }^{32}$ Mommsen. II, 26. I, 71. 
antes de enfrentarlos con sus acusadores y darle la oportunidad de defenderse" (supra, Festo ante Agripa y Berenice).

Pero, sin duda observando la formalidad procesal usual, el gobernador esperará para poner en marcha el proceso a que lleguen los acusadores. Mientras tanto, lo pone bajo custodia en el pretorio, es decir, en las mismas instalaciones del edificio en que se residía el tribuno y se celebraban las audiencias. La custodia bajo la cual fue puesto se trataba de la "custodia libera", es decir, libre de arresto y/o ligaduras que los magistrados podían disponer en ciertas circunstancias sea por la naturaleza del asunto, la personalidad del encartado o deficiencias de seguridad en las cárcel pública y podía efectivizarse en una casa particular, en la casa del magistrado o, como en este caso, en el mismo pretorio. "De custodia reorum Proconsul aestimare solet, uttrum in carcerem recipienda sit opersona, an militi tradenda, del fideiussoribus committenda, vel etiam sibi. Hoc autem pro criminis, quod obiicitur, qualitate, vel propter honores, aut propter amplissimas facultates, vel pro innocentia personae, vel pro dignitate eius, qui accusatur, facere solet" En cuanto a la custodia de los reos suele estimar el procónsul si la persona haya de ser recluida en la cárcel o haya de ser entregada a los militares o encomendada a fiadores, o aún a ella misma. Más esto suele hacerlo atendiendo a la calidad del delito que se le imputa, o a la honorabilidad, o a las grandes facultades, o a la inocencia de las personas o a la dignidad del que es acusado $\left({ }^{33}\right)$.

Comparecen días después el sumo sacerdote con algunos ancianos y un abogado llamado Tértulo que habían convocado para presentar la acusación y que más que como "advocatus" pareciera haberse comportado como "orator". Luego de un breve y obsequioso introito dirigido al gobernador como indican las normas de la obsecuencia, o un "exordio pomposo" según la Oratoria, el abogado ingresa en la "exornación o elocución" enfatizando que Pablo era una verdadera peste, que suscitaba disturbios y era uno de los dirigentes de la secta de los nazarenos, como si ser de tal "secta" fuera un delito; para colmo, había intentado profanar el templo. En suma, una pulida pieza que no acredita nada. Tanto es así que el mismo abogado pide que el gobernador lo interrogue para reconocer que los cargos son bien fundados $\left({ }^{34}\right)$.

El acusado no podía ser condenado sin ser oído, pero éste no podía dejar de responder. Recordemos la sorpresa de Pilatos cuando Cristo se niega a responder de los cargos que le formulan $\left({ }^{35}\right)$. El abogado, a falta de otros elementos, recurre a una eventual confesión de Pablo, que se defiende en términos religiosos y desafía a los acusadores para que concreten de qué delito lo acusan. La intervención de

\footnotetext{
${ }^{33}$ Ulp. De oficio Proconsulis. Libro II. Dig. XLVIII,III; Mommsen, op.cit.1, 310,337.

${ }^{34}$ Scialoja, V: Procedimiento civil romano. Ejea.\&22; Cebeira A: Lecciones de Oratoria. Librería El Foro. HE: 24,7.

${ }^{35}$ Mateo 27,11; Marcos 15,1.
} 
defensores en los procesos ante gobernadores de provincias y/o el tribunal del Emperador no era muy frecuente, pero la "autodefensa" era un derecho sólidamente establecido por la costumbre y respetado por los órganos jurisdiccionales. Al reclamar Pablo, ejerciendo su "autodefensa", que especificaran los delitos objeto de la acusación, sin duda ponía hábilmente a los acusadores contra las cuerdas porque para ser condenado en esa sede era necesario la concurrencia de alguna figura penal legalmente prevista o, en último caso y de recurrirse a la "coecitio", de algún acto grave contrario al orden público, pero todo lo referido por el abogado versaban sobre cuestiones religiosas que no constituían en absoluto delito para el derecho romano vigente.

Félix posterga la causa esperando para expedirse a que viniera el tribuno Lisias desde Jerusalén ordenando al centurión "que custodiara a Pablo, pero dejándole cierta libertad y sin impedir que sus amigos lo atendieran”. Días después y con su mujer Drusila, manda llamar a Pablo y se ponen a conversar acerca de la fe en Jesucristo, pero cuando se introduce en temas poco agradables como la justicia, la continencia y el juicio futuro, lo despacharon con la promesa de volver a llamarlo. Así lo tuvo en espera durante dos años y si lo llamaba no era precisamente para conversar sobre la salvación eterna sino para insinuar lo conveniente que sería alguna "gratificación". Como demostrando el valor de la esperanza, si la custodia hasta entonces había sido "libera", se torna más flexible todavía. Sin embargo, pese a la carta del tribuno en la que se consigna que no había cargo alguno que mereciera muerte o prisión y a la cierta libertad que le otorga Félix, ante Agripa Pablo se lamenta de estar con cadenas. Si así fuere, Félix habría obrado ilegalmente $\left.{ }^{36}\right)$.

El centurión al que Félix encomienda la custodia de Pablo revistaba en la categoría en cierto modo política de "frumentarius", que servía de enlace entre jefaturas militares y cargaba una gran responsabilidad y graves castigos en caso de fugas de presos. "Milites si amiserint custodia, ipsi in periculum deducuntur; nam Divus Adrianus Statilio Secundo legato rescripsit, quoties custodia militibus evaserit, exquiri oportet, utrum nimian negligentia militum evaserit, an casu,et utrum unus ex pluribus, an una pluses; et ita demum afficiendos suplicium milites quibus custodiae evaserint, si culpa eorum nimia deprehendatur, alioquin pro modo culpae in eos statuendum" Si los militares hubieren perdido a los presos, incurren ellos en responsabilidad; porque el Divino Adriano respondió por escrito al legado Statilio Segundo, que siempre que un preso se hubiere escapado de los soldados, se debía inquirir si se había escapado por demasiada negligencia de los militares, o por casualidad, y si uno solo de muchos o muchos juntos; y que se

${ }^{36}$ HE: 23,29; 24,23; 26,29; Renan, op.cit.354. 
debía castigar con suplicio a los soldados a quienes se les hubiere escapado los presos solamente si se descubriera demasiada culpa en ellos pues en otro caso se habría de determinar contra ellos con arreglo su culpa" $\left({ }^{37}\right)$.

La postergación de la causa estaba dentro de las amplias facultades del magistrado que no tiene plazos, puede sobreseerla, abandonarla o retomarla, discrecionalidad de la que, aunque hayan perdido tales facultades, suelen no privarse los magistrados actuales así como tampoco de la esperanza de alguna gentileza.

Llamar al prisionero, platicar con él, tratar de convencerlo, devolverlo una y otra vez a la prisión durante cierto tiempo, tal tarea de seducción y desgaste fue muy frecuentada en los procesos a los cristianos. Haber convencido al reo y concluir su período sin haber condenado a ninguno era un timbre de eficacia y honor para muchos magistrados. En este caso las motivaciones de Félix que quedaron al descubierto no eran tan meritorias y como en política también los días interpelan por el hombre, al cabo de los dos años hubo de dejar su estrado a su sucesor Festo, personaje firme y justo según Josefo $\left({ }^{38}\right)$.

Tres días después de asumir el cargo, Festo sube a Jerusalén y enseguida sacerdotes y judíos principales le ponen a consideración la causa de Pablo reclamando que lo trajeran de nuevo a esta ciudad; pero el gobernador considera que Pablo debía seguir bajo custodia en Cesarea y les indica que cuando él regrese, le acompañen y presenten formalmente la acusación. Al día siguiente del regreso se celebra la audiencia en la que se aducen numerosas y graves imputaciones que, no obstante, no pudieron probar. La apreciación de la prueba era de exclusivo y discrecional arbitrio del magistrado, pero a los acusadores le incumbía la carga. Pablo se defiende alegando que no ha cometido falta alguna ni contra la ley judaica, ni contra el templo ni contra el Emperador. Festo, que al parecer no era tan firme como dijera Josefo o era políticamente maleable, no quiere enemistarse con los judíos y le propone a Pablo ser juzgado en Jerusalén, a lo que el acusado responde: "Estoy delante del tribunal del Emperador y es aquí donde debo ser Juzgado si soy culpable y he cometido delito no me niego a morir, pero si las acusaciones que hacen los judíos contra mi carecen de fundamento, nadie tiene derecho a entregarse a ellos. Apelo al Emperador". Festo después de haber consultado con su "Consilium", respondió: "Ya que apelaste al Emperador, comparecerás ante él" ( $\left.{ }^{39}\right)$.

Si Félix había procedido ilegalmente, Festo pareciera también haber incurrido en exceso al mantener prisión de Pablo. Los Hechos lo explican por el deseo de congraciarse con los judíos, pero si se tiene en cuenta el clima adverso

\footnotetext{
${ }^{37}$ Mommsen, op.cit 1,319; Dig: XLVIII, III,12.

${ }^{38}$ Antiq.II,XIV,1.

${ }^{39}$ HE: 25.10 .12 .
} 
que se había creado contra el apóstol y la emboscada para matarlo que se estaba tramando, bien puede haber sido por razones prudenciales de seguridad para un ciudadano romano y, en este supuesto, habría obrado correctamente. En todo lo demás, salvo la propuesta un tanto cínica de volver a Jerusalén para ser juzgado, se condujo conforme a derecho. "Yo les respondí que los romanos no tienen la costumbre de entregar a un hombre ante de enfrentarlos con sus acusadores y darles oportunidad de defenderse". Esta era la regla de oro y la observó a raja tablas. No habiéndose probado nada y hecha la apelación, consulta al "consilium" y contesta con la "fórmula" de práctica: "Ya que apelaste ante el Emperador, comparecerás ante el". La negativa a ser juzgado en Jerusalén y la apelación de Pablo al Emperador le vino de perlas al gobernador para sacarse el asunto de encima que, por otra parte, no tenía alternativa pues la violación del derecho de apelación y/o el impedimento a un ciudadano que pretendiera marchar a Roma para defenderse, lo hubiera hecho incurrir en "vis publica", delito gravemente castigado $\left({ }^{40}\right)$.

Antes de ser enviado a Roma, pasan por Cesarea el rey Agripa y Berenice. Festo les narra lo ocurrido, el rey manifiesta su deseo de oír a Pablo. Llevado a su presencia les prodiga un largo discurso que, al tocar el tema de la resurrección de los muertos, le cayó a Festo tan disparatado como para tildarlo de loco que ha perdido la cabeza. No obstante, el rey (que casi terminado convencido y convertido) y su esposa lo escuchan con atención y cuchichean entre si que Pablo no había hecho nada reprobable, a punto tal que el primero le manifiesta al gobernador como lamentando la situación: "Podría ser dejado en libertad, si él mismo no hubiera apelado al Emperador".

En realidad, este pasaje podría ser considerado como un "dispendio jurisdiccional" porque nada tenían que hacer el rey y su esposa en este caso, salvo el interés por escuchar a Pablo y la obsecuencia del gobernador por complacerlos. Si el reo hubiera sido judío y acusado de infracciones puramente religiosas, Agripa podría haber intervenido como "tetrarca de Galilea" (i.e de una cuarta parte) y, de haber condena a pena capital de acuerdo con las normas del Talmud, ejecutarla previa conformidad del gobernador. "A nosotros no nos está permitido dar muerte a nadie”, habían alegado los judíos ante Pilatos $\left({ }^{41}\right)$ en el proceso a Jesús. Pero, convocado Pablo por orden del tribuno Licias, éste comprueba que "se lo acusaba por cuestiones religiosas relativas a la ley de los judios y que no había ningún cargo que mereciere la ley de muerte o prisión. Seguramente por no conocerla, el tribuno no estaba en condiciones de juzgar por delitos y penas de la

\footnotetext{
${ }^{40}$ HE: 25.16. De Francisci, P: Síntesis historica del Derecho Romano. Ed.Revista de Derecho, privado, pág. 604 .

${ }^{41}$ Juan, 18,31.
} 
ley mosaica, pero la mención de "ningún cargo"” que merecieren pena capital y la defensa de Pablo ante Festo ("Yo no he cometido ninguna falta contra la Ley de los judios, ni contra el templo, ni contra el Emperador") permiten presumir que los acusadores, quizá como un recurso por si no procedían cargos por su ley, procedieran por la romana, habrían introducido en sus acusaciones también cargos de delitos contra el Emperador para presionar así al magistrado, como hacía ya años habían amedrentado ("si no haces eso, eres enemigo del César) a Pilatos $\left({ }^{42}\right.$ ). Pablo, ciudadano romano, no hubiera podido ser juzgado por la ley y autoridades religiosas judías sino por las leyes y autoridades romanas. Que podría ser dejando en libertad fue una mera opinión o quizá expresión de deseos del tetrarca, no una sentencia. Pero Festo, a más de la complacencia para con el rey y Berenice, tenía otro motivo que confiesa sin tapujos: "Como no tengo nada preciso que escribir (elogium) sobre él al Superior (Emperador), lo hice comparecer ante ustedes, especialmente ante ti, rey Agripa; así, después de este interrogatorio, yo tendré algo para informar. Porque me parece absurdo enviar a un prisionero sin indicar al mismo tiempo los cargos que se le imputan". $\left({ }^{43}\right)$.

Acompañado por un centurión de nombre Julio, que trató a Pablo con suma deferencia e incluso lo salvó de que los marineros en una ocasión lo mataran y luego de variadas peripecias, Pablo llega a Roma donde recibió autorización para alojarse en una casa particular con un soldado de custodia y siguió predicando la doctrina de Cristo. Los Hechos concluyen aquí sin mencionar nada sobre el proceso $\left({ }^{44}\right)$.

8: El silencio de los Hechos pareciera haber sido observado por toda la literatura posterior. Salvo la certeza de no haber sido condenado por el tribunal del Emperador, haber recuperado la libertad, haber sufrido el martirio bajo Nerón y algunas otras circunstancias que pueden extraerse de sus célebres Cartas, todo lo demás queda en niveles de sagas y tradiciones sin apoyaturas documentales. Puede también haber contribuido a esta laguna histórica el hecho de que en medio de las querellas intestinas de la naciente iglesia, hasta el siglo III la figura de Pablo no adquirió mayor relevancia.

Los textos de historia de la Iglesia y los comentadores de los libros sagrados están contestes en que Pablo logra la libertad en Roma pero difieren y son confusas las explicaciones sobre las razones jurídicas que habrían determinado la liberación. Veamos algunos ejemplos:

"Al cumplirse dos años de la custodia militar, Pablo quedó seguramente en libertad. Así lo determinaba la ley en caso de que no prosperara la acusación”, se

\footnotetext{
42 Juan, 19,12.

${ }^{43}$ HE: $25,27$.

${ }^{44}$ HE: 28,30 .
} 
anota en "El Libro del Pueblo de Dios - La Biblia" en el pasaje de la cautividad en Cesarea bajo Félix. Se trata de "custodia militar" y la libertad sería la consecuencia de una ley, que no se identifica, según la cual no podía superar los dos años.

"No cabe duda que el apóstol fue absuelto y puesto en libertad en el año 63 ", asegura Straubinger, lo que en clave procesal presupone que hubo un proceso y un pronunciamiento (absolución) del tribunal y, si Pablo llegó entre el 60 y 61, habría estado dos años o más en proceso.

"Finalmente tras un año de prisión mitigado, el apóstol fue absuelto y puesto en libertad" comenta Ruiz Bueno. Para este autor Pablo llegó en el 62 y se trata de una "prisión mitigada" que no excede de un año.

"Bienium autem expleto", pasados dos años reza el versículo 24.27 de los Hechos al referirse al tiempo en que Félix tuvo prisionero a Pablo y en la "Nueva Biblia de Jerusalén" se anota: "griego dietia (= bienium) esta palabra, que se halla también en 28.30 parece tomarse como término técnico en derecho, la duración máxima de una prisión preventiva. Al cabo de ese plazo, de no haber condena, Pablo lógicamente tendría que recuperar su libertad. Es lo que probablemente ocurrió en Roma". Son dos años y prisión preventiva.

"La tradición más antigua afirma igualmente que, a los dos años de su llegada a Roma, Pablo fue puesto en libertad. Una cautividad tan suave como la que sufrió Pablo en esos años no podía terminar de otro modo que con la libertad", deduce un historiador moderno. Tenemos una "cautividad suave" y como fundamente una antigua tradición.

Llegado a Roma, se le permite residir en una "casa particular con un soldado de guardia y Pablo-concluyen los Hechos- permaneció por espacio de dos años enteros en la casa que había alquilado (in suo conducto), en donde recibía a cuántos iban a verle predicando el reino de Dios y enseñando con toda libertad, sin que nadie se lo prohibiese, lo tocante a nuestro Señor Jesucristo".

Lo cierto es que Pablo desde su extraña situación de cautividad domiciliaria pudo desarrollar sus actividades apostólicas sin dificultades y viviendo de lo suyo. Sin embargo, en el año 63 escribe su Carta a los Filipenses manifestando que en el pretorio es conocido que sus cadenas son por la causa de Cristo y espera que se aclare su situación para ir a verlos. En la segunda Carta a Timoteo sigue mencionando sus cadenas, pero esto ocurría entre los años 66-67 cuando estaba en la cárcel mamertina antes de su martirio $\left({ }^{45}\right)$.

Si Pablo pasa dos años ante Félix y Festo y dos en Roma hasta el 63 en que es librado, su cautividad habría durado 4 años. Pero si pudo alquilar y vivir en

${ }^{45}$ El Libro del Pueblo de Dios. Trad-Levoratti-Trusso: HE, nota 28,30. Straubinger: Op.cit, nota final. RB, 212. Nueva Biblia de Jerusalén. Desclee de Bouver: HE: 24.27;28.30 y nota. HE: Hechos.28.30-31. BAC: I,IV,IV). San Pablo: Carta a los Filipenses 2,23; 2da.a Timoteo 1,17- 2.9. 
una casa particular, mantenerse con propios medios (era de profesión tapicero y venía de desarrollar ese oficio en Corinto con Aquila y Priscila), recibir visitas a voluntad y enseñar con toda libertad y sin ningún obstáculo, según el Epilogo de los Hechos, su situación en la Urbe aparece muy extraña y poco acorde con un estado cautividad; salvo la presencia de un soldado, se asemeja más a una situación de libertad plena.

Hay muy pocas noticias de cómo haya proseguido, si es que prosiguió, el proceso. Lucas concluye la narración de los Hechos informando que Pablo estuvo en la situación descripta por lo menos dos años en Roma. Ahora bien, Lucas escribe los Hechos después de ese lapso y sobrevive a San Pablo por lo que no se aprecia razón para que no haya narrado el "proceso ante el Emperador", como lo hizo de las actuaciones frente a Félix y Festo, si tal proceso realmente se hubiere sustanciado.

Con respecto al plazo de uno o dos años que una vez vencido hubiere abierto la puerta de la libertad a Pablo, los comentadores de los Hechos y los autores varios omiten toda referencia a alguna norma que así lo hubiere estipulado y hubiere sido de aplicación al momento de su cautiverio y proceso. No haberla tampoco hallado para este trabajo nos siembra la duda si es por defecto e información o porque la tal norma no existió, salvo por fuente consuetudinaria. Mommsen, luego de comentar que en Roma no se conoció la cárcel como pena y que el arresto correspondía a la esfera de la coerción del magistrado por lo que, en principio, quedaba librado a su arbitrio, sin perjuicio de alguna eventual regulación en cuanto a los motivos, expresa: "En general, a causa del carácter discrecional del arresto, no se admitían tocante al mismo limitaciones obligatorias en cuanto al tiempo que había de durar; se decretaba siempre hasta nueva orden y, por lo tanto, podía cesar en cualquier momento, pero también podía dilatarse indefinidamente; lo regular era, sin embargo, que se hiciera uso de él como medida transitoria y provisional".

Los datos sobre el tiempo de los procesos son muy escasos y se refieren a la prescripción de las acciones. Como corolario podría estimarse, como lo hace Mommsen, que la duración de los procesos tendía a no ser desmedida. Disposiciones de Julio César fijando cortos plazos fueron ampliados con posterioridad haciéndose costumbre que el tribunal interviniente estableciera los plazos de inicio y fin del proceso, por lo general entre uno y dos años. Se encuentran sí disposiciones concretas que parecieran receptar esta costumbre, pero ya en tiempos del Código de Justiniano:

"Noverim iudices cuilibet culmine honorive praesidentes, necessariis utrique parte intra certum tempos criminales causas limitandas". Sepan los jueces que presidan con cualquier categoría u honor qu las causas criminales han de ser limitadas dentro de cierto tiempo.

"Criminales causa intra duos anos a contestatione litis connnumerandos finiri censemos, nec ulla ocasione ad ampliora produci tempora, sed post bienio 
excessum, minime ulterius lite durante, accusatum absolvi, scientibus iudicibus eorumque officiis, quod, si litigatoribus admonentibus ipsi litis introductionem vel examinationem distulerint, poena vicenarum librarum auri ferientur". Mandamos que de todos modos se terminen las causas criminales dentro de dos anos contaderos desde la contestación del litigio y que en ninguna ocasión se prorrogue a más amplio plazo, sino que después de transcurso del bienio, no durando ya más el litigio, sea absueltp el acusado, sabiendo los jueces ysus oficiales que,si instando los litigantes hubieren ellos mismo dilatado la presentación o el examen del litigio, sean castigados con la pena de veinte libras de oro $\left({ }^{46}\right)$.

Me permito intentar dos hipótesis: a) si bien el proceso ante el Emperador debía ser instrumentado por "cognición", los funcionarios imperiales y mucho menos el Emperador pudieron haberse interesado en activar una causa contra un ciudadano romano y por una cuestión meramente religiosa, salvo que hubieren aparecido los lejanos acusadores de una remota provincia del Imperio, que no se tiene noticia hayan aparecido. Los judíos principales que fueron a verlo, lejos de acusarlo, estuvieron todo el día conversando sobre el Reino de Dios, aclararon que no habían recibido carta alguna en su contra, algunos se convirtieron y otros se fueron discutiendo entre ellos, sin que a ninguno se le pasara por la cabeza la idea de acusarlo $\left({ }^{47}\right)$. Probablemente ni siquiera haya existido proceso y por ende absolución. Sin acusadores que la activaran, la causa ha de haber entrado en vía muerta y al cabo de un tiempo Pablo, del que quizá los funcionarios ni se acordaran, habría quedado de hecho totalmente y sin más trámite desvinculado. b) las cadenas que mortifican a San Pablo pueden haber tenido el sentido puramente enfático o metafórico de encontrarse legalmente acusado y condicionado injustamente. No es muy verosímil que una persona - ciudadano romano para más - pueda alquilar una casa, vivir de sus medios, recibir a quien le plazca, hacer proselitismo y seguir predicando todo aquello por lo que se le había acusado, encontrándose físicamente encadenado. Si existía alguna ley o costumbre que limitara la prisión preventiva a dos años, Pablo tuvo que haber recuperado la libertad antes o al momento de llegar a Roma pues ya los había cumplido en Cesarea. Como la causa había sido elevada al Emperador, se imponía la custodia durante el viaje. Al llegar a Roma, el centurión debe haber respirado aliviado, entregado a Pablo, quizá ya hecho un amigo, y a los demás prisioneros y regresado a sus cuarteles. Mientras tanto, por precaución o seguridad o "por las dudas", le pusieron una discreta vigilancia apenas un soldado para que lo custodiara- como hoy tantos jueces y funcionarios tienen algún policía de custodia en la puerta de sus domicilios. Sería en el peor de

\footnotetext{
${ }^{46}$ Mommsen, op.cit. I, 308,465. Código. IX,XLIV, 2,3. Vid.etiam Cód. IX IV A,6 1/6; B.2.3.4.

${ }^{47} \mathrm{HE}: 28.23$.
} 
los supuestos de una "libertad vigilada". Como se explicará seguidamente, el tribunal del Emperador no estaba obligado y podía rehusar atender las causas. Sustanciar un proceso por cuestiones de una religión casi desconocida contra un ciudadano romano, sin acusadores y sin cargos penales previstos por leyes romanas, no debe haber suscitado interés alguno entre los funcionarios del palacio imperial, que quizá ni se hayan dignado considerar el asunto. Total, el hombre estaba prácticamente libre, lo dejaron así nomás y la causa murió el sueño de los justos.

9: La vía más importante para el ejercicio de la jurisdicción penal durante el Principado fue el procedimiento ante el Tribunal del Emperador cuya función era cuádruple al actuar: 1: como primera y única instancia. 2: por delegación (legados imperiales, gobernadores de provincias, funcionarios especiales). 3: como tribunal de alzada de resoluciones de los gobernadores y delegados. 4: dando respuestas a petitorios sobre temas sometidos a su consulta.

La competencia del tribunal abarcaba a las "Provincias Imperiales" ya que, dada la estructura de la "Diarquía", las "Provincias Senatoriales" aplicaban el procedimiento ante el Senado. Regía para los ciudadanos romanos incluso de "utroque ordo", a los ciudadanos de ciudades libres y a los súbditos de principados clientes de Roma.

En principio comprendía el juzgamiento de delitos militares, luego se amplia a delitos comunes de militares y finalmente se convierte en proceso penal ordinario, incluso para delitos cometidos por gobernadores y funcionarios.

Con Augusto, el emperador reasume el "imperium" absoluto anterior a la aparición de la "provocatio ad populum". Si se agrega a este basamento la conservación en el procedimiento de algunas características de su origen como "derecho de guerra", se explica la total dependencia del arbitrio del Emperador, que se encontraba "legibus solutus" y tanto podía rehusarse a conocer el asunto como derivarlo o resolverlo a contrapelo de las normas vigentes. Era un procedimiento por "cognición" transformado en "extraordinario" en el que el particular en el mejor de los casos oficiaba de denunciante y las posibilidades de defensa estaban muy acotadas; la muy rala intervención de abogados, por regla general excluidos en esta sede penal, las limitaba de hecho a la autodefensa.

El Emperador atendía las causas en el "auditorium" o sala imperial y, aunque fuere optativo, generalmente recurría al asesoramiento de expertos o funcionarios permanentes o temporarios, honorarios o rentados que formaban el "consilium Principis", integrado mayoritariamente por miembros de la orden de los "equites". Vimos supra cómo Festo, antes de conceder la apelación al Emperador, reúne y consulta a su Consejo. En este órgano consultivo fueron adquiriendo relevancia los comandantes de la guardia imperial, los "prefectos del pretorio", de moto tal que a la época de los Severos los más grandes juristas (Papiniano, Paulo, Ulpiano) fueron distinguidos con esa dignidad. El 
"Consilium" presentaba un "periculum" o proyecto de resolución del caso que, especialmente cuando el Emperador lo había encomendado a algún funcionario en particular, era como una sentencia anticipada.

Al intervenir el tribunal como 1ra. Instancia, el Emperador resolvía discrecionalmente y sin posibilidad de apelaciones. Como tribunal de Alzada aprobaba o desaprobaba las penas de reclusión y, en casos de pena capital, gozaba del "derecho de gracia": los gobernadores y delegados podían sentenciar a muerte pero debían consultar al emperador si podían ejecutarla o no.

Los famosos "rescriptos" de los Emperadores fueron las respuestas a petitorios o consultas elevados por gobernadores y otros funcionarios; conformaron verdaderos "precedentes" en la materia de que se tratare.

Desde el siglo anterior al Principado el ciudadano romano gozaba del "derecho de provocación" para recusar a los tribunales de los gobernadores de Provincia, pero durante el principado la provocación se hizo tan frecuente que los gobernadores fueron adoptando la práctica de enviar directamente los asuntos al tribunal imperial para que allí fuesen juzgados.

El gobernador Festo tenía atribuciones para declarar la inocencia o la culpabilidad de Pablo, pero en este último supuesto debía abstenerse de pronunciar una sentencia condenatoria en forma y elevarlo ante el tribunal del emperador. No se trataba estrictamente de un fallo (sentencia) en sentido técnico-jurídico sino de una propuesta presentada al emperador que podía acogerla en todo o en parte, anularla, modificarla, etc. Si el gobernador Festo hubiere sentenciado el caso, el recurso de Pablo se hubiere tratado técnicamente de una "apelación", es decir, llevar disconformidad de una cuestión decidida en un grado a otro superior para que vuelva a tratarla. Pero en realidad de lo que Pablo hizo uso fue recurrir al "derecho de gracia" imperial que, en términos actuales, se trataría de una "recusación", o "declinatoria de competencia" es decir, un recurso procesal para apartar al gobernador del asunto y ser decidido por el Emperador que, por otra parte, estaba obligado a conceder. De todos modos en el derecho romano "apellatio" y "provocatio" se usaron como sinónimos $\left({ }^{48}\right)$.

Sin duda Pablo le ahorró trabajo el gobernador, pero es muy probable que, en virtud de la práctica que se estaba afianzando y lo incordioso del asunto, el gobernador lo hubiera mandado con prisionero y todo al tribunal del Emperador.

Distinto fue el caso de Jesús. El derecho romano no se aplicaba a los judíos que en materia religiosa seguían sujetos a su derecho canónico consignado en el Talmud. El Sanedrín como tribunal judío, podía aplicar la pena de acuerdo con su

${ }^{48}$ Scialoja V, op.cit \& 29. 
legislación, pero como institución de un pueblo ocupado, no tenía derecho a hacer ejecutar una sentencia sin consentimiento de la autoridad penal romana. "A nosotros no nos está permitido dar muerte a nadie", alegaron, como se citó supra, los que acusaban a Jesús ante Pilatos que, tratándose de supuestos delitos de naturaleza religiosa, lavándose las manos lo que hizo fue dar vía libre (exequatur) para la ejecución de la condena dictada por el Sanedrín $\left({ }^{49}\right)$. A Pablo como ciudadano romano le alcanzada el "derecho de gracia" del emperador. ¿A Jesús le habría también amparado?. Si tenemos en cuenta que, según Mommsen, el gobernador tenía atribuciones para enviar a los peregrinos ante el tribunal del emperador (en ese momento Tiberio), pero que tal envío no tenía lugar sino en casos excepcionales $\left({ }^{50}\right)$, la respuesta sería afirmativa; no obstante, el hecho de que ni siquiera se haya mencionado esa posibilidad indica a las claras que el acontecimiento más excepcional de nuestra historia fue apenas un hecho menor para los romanos.

\footnotetext{
${ }^{49}$ Jn 18.31; José. Antiq. XX,IX,1. Talmud de Jer. Sank.I,1. Renan, 271.

${ }^{50}$ Penal Romano, I,249.
} 